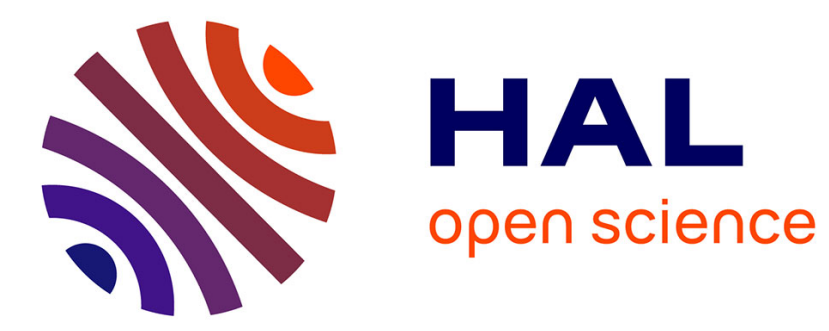

\title{
Sequential processing during noun phrase production
}

\author{
Audrey Buerki, Jasmin Sadat, Anne-Sophie Dubarry, F. -Xavier Alario
}

\section{To cite this version:}

Audrey Buerki, Jasmin Sadat, Anne-Sophie Dubarry, F. -Xavier Alario. Sequential processing during noun phrase production. Cognition, 2016, 146, pp.90-99. 10.1016/j.cognition.2015.09.002 . hal01432273

\section{HAL Id: hal-01432273 \\ https://hal.science/hal-01432273}

Submitted on 10 Apr 2019

HAL is a multi-disciplinary open access archive for the deposit and dissemination of scientific research documents, whether they are published or not. The documents may come from teaching and research institutions in France or abroad, or from public or private research centers.
L'archive ouverte pluridisciplinaire $\mathbf{H A L}$, est destinée au dépôt et à la diffusion de documents scientifiques de niveau recherche, publiés ou non, émanant des établissements d'enseignement et de recherche français ou étrangers, des laboratoires publics ou privés. 
Bürki, A., Sadat, J., Dubarry, A. S., \& Alario, F. X. (2016). Sequential processing during noun phrase production. Cognition, 146, 90-99.

https://doi.org/10.1016/j.cognition.2015.09.002

\section{Sequential processing during noun phrase retrieval}

Audrey Bürki (corresponding author), audrey.buerki@unige.ch

(1) Faculté de Psychologie et des Sciences de l'Education, Université de Genève, Bd du Pont d'Arve 42, 1205 Genève, Switzerland, 00413798321

(2) Aix Marseille Université, CNRS, LPC UMR 7290, 3, Place Victor Hugo, 13331, Marseille, France

Jasmin Sadat, jasmin.sadat@upf.edu

(1) Aix Marseille Université, CNRS, LPL UMR 7309, 5, Avenue Pasteur, 13100 Aix-en-Provence, France, 0033413552700

(2) Aix Marseille Université, CNRS, LPC UMR 7290, 3, Place Victor Hugo, 13331, Marseille, France

Anne-Sophie Dubarry, anne-sophie.dubarry@univ-amu.fr

Aix Marseille Université, CNRS, LPC UMR 7290, 3, Place Victor Hugo, 13331, Marseille, France, 0033413550960

F.-Xavier Alario, francois-xavier.alario@univ-amu.fr

Aix Marseille Université, CNRS, LPC UMR 7290, 3, Place Victor Hugo, 13331, Marseille, France, 0033413550972

Running title: Sequentiality in noun phrase retrieval 


\section{Acknowledgements}

We thank the "Féderation de Recherche 3C" (Aix-Marseille Université) for institutional support.

\section{Funding and grant-awarding bodies}

This work was supported by the Swiss National Science Foundation under grant nIZKOZ1146008; the University of Geneva (Subside tremplin); the European Research Council under the European Community's Seventh Framework Program (FP7/2007-2013 Grant agreement n॰263575), and the Brain and Language Research Institute (Aix-Marseille Université : A*MIDEX grant ANR-11-IDEX-0001-02 and LABEX grant ANR-11-LABX-0036). 


\begin{abstract}
This study examined whether the brain operations during the access to the phonological forms of successive words in multi word noun phrase production takes place sequentially or simultaneously. German speakers named pictures while ignoring a written distractor superimposed on the picture (picture-word interference paradigm) using the definite determiner and corresponding German noun. The gender congruency and the phonological congruency (i.e., overlap in first phonemes) between target and distractor were manipulated. Naming responses and EEG were recorded. The behavioural performance replicated both the phonology and the gender congruency effects (i.e., shorter naming latencies for gender congruent than incongruent and for phonologically congruent than incongruent trials). The phonological and gender manipulations also influenced the EEG data. Crucially, the two effects occurred in different time windows and over different sets of electrodes. The phonological effect was observed substantially earlier than the gender congruency effect. This finding suggests that accessing the phonological content of determiner and nouns during determiners noun phrase production occurs at least partly sequentially. In addition, the present findings reveal that the phonological form of the noun is accessed before that of the determiner.
\end{abstract}

Keywords: EEG, language production, multi-word utterances, Picture-word interference 


\section{Introduction}

Psycholinguistic models of language production are typically conceived as a series of processing stages involving different types of knowledge: the concept to be expressed, the corresponding syntactico-semantic representation (grammatical encoding process), the phonological representation (phonological encoding process) and corresponding abstract gestures (phonetic encoding). The broad aspects of such organization are used (quite consensually) to account for the production of isolated words. In most linguistic events, however, speakers do not produce single words, rather, they combine words in larger utterances. Importantly, it is not granted that the production of multi-word utterances will amount to performing all the single-word steps for each word consecutively.

Behavioural studies have indicated that speakers can activate several words, both at the grammatical and phonological encoding levels, before they start articulating an utterance (e.g., Allum \& Wheeldon, 2007; Costa, Navarette, \& Alario, 2006; Damian \& Dumay, 2009; Konopka, 2012; Lee, Brown-Schmidt, \& Watson, 2013; Martin, Crowther, Knight, Tamborello, \& Yang, 2010; Meyer, 1996; Oppermann, Jescheniak, \& Schriefers, 2010; Schnur, Costa, \& Caramazza, 2006; Smith \& Wheeldon, 1999; Wheeldon, Ohlson, Ashby, \& Gator, 2013). Much remains to be described, however, regarding the temporal alignment of encoding processes for the different words within such planning units. In particular, a central and open issue to understand multi-word production concerns the amount of sequentiality vs. simultaneity in the encoding of the different words at each encoding step.

Consider for instance the noun phrases the dog, or the black dog. Are the words planned, encoded and selected one after the other or simultaneously? If the encoding occurs sequentially, a related issue would concern the order in which the words are accessed and encoded. For instance, it has been hypothesized that during the grammatical encoding process, lexical representations (i.e., lemmas) for the different words are processed in parallel (Schriefers, 1992; Kempen \& Huijbers, 1983). At the phonological level of encoding, several authors have hypothesized that word representations (known as "lexemes") are activated and encoded sequentially within phonological planning units, according to the order in which they are to be produced (see Dell, 1986; Meyer, 1996). In early models of sentence processing (e.g., Garrett, 1975, see also Bock, 1987), by contrast, the phonological content of early occurring determiners was specified only after 
content words had been phonologically encoded. The empirical evidence available so far does not allow providing precise answers to these questions.

Distinguishing between simultaneous and serial processes on the basis of chronometric evidence is a notoriously complex endeavour (e.g., Townsend \& Wenger, 2004). Behavioural paradigms only record the endpoint or final product of the production process. Consider for example a study by Alario, Costa, \& Caramazza (2002a, 2002b, see also Levelt, 2002, for comments) in which they observed that latencies of determiner+adjective+noun (e.g., the blue kite) phrases were influenced by the lexical frequency of both the adjective and the noun, and that the two effects were additive. According to the authors, these findings are compatible with the view that adjectives and nouns are processed in a sequential fashion. However, these findings do not allow rejecting an alternative view in which the two representations are accessed simultaneously, and where the ease of processing one representation depends on the ease of processing the other one (as suggested for instance by Schriefers, de Ruiter, \& Steigerwald, 1999).

Neurophysiological recording techniques (e.g., Electroencephalography, EEG, and Magnetoencephalography, MEG) provide fine-grained temporal information about on-going neural and cognitive process(es). They can be used to gain further insights on the coordination of encoding processes in multi-word production. using). Recent advances in electrophysiological methods have allowed psycholinguists to examine the time course and neural dynamics of overt word production (for reviews see Ganushchak, Christoffels, \& Schiller, 2011, Indefrey, 2011; Llorens, Trébuchon, Liegeois-Chauvel, \& Alario, 2011, and Strijkers \& Costa, 2011; Munding, Dubarry, \& Alario, submitted). These studies have provided novel insights into the time course of encoding processes during isolated word production. Yet, within this thread of research, very few neurophysiological studies have investigated encoding processes for multi-word utterances. PyIkkänen, Bemis, and Blanco Elorrieta (2014) used MEG to compare the production of isolated nouns and adjective+noun phrases. They observed differences in neural activity between the two utterance types starting at about $180 \mathrm{~ms}$ after picture onset, which they associated with combinatory processes (grammatical encoding). In another study, Eulitz, Hauk, \& Cohen (2000) compared the EEG activity during picture naming with isolated nouns and coloured adjective+noun phrases and found no difference in the EEG signal between the two types of utterances. By contrast, in a recent study, Bürki and Laganaro (2014) reported longer periods of stable electrophysiological activity for noun phrases with a determiner (e.g., the big cat, the cat) than 
for isolated nouns from around 190 to $300 \mathrm{~ms}$ after picture onset, and longer periods of stable electrophysiological activity for noun phrases with an adjective than for those without from 530 ms after picture onset to 100 ms before the onset of articulation.

Beyond some empirical discrepancies, all three studies compare different utterance types to explore the encoding processes that may differ between them (e.g., presence vs. absence of multiword grammatical encoding). As such, they are not informative on our issue of interest, the temporal alignment of the retrieval and selection of the different words comprised in an utterance.

The current study

The goal of the present study is to investigate the time course of retrieval processes that lead to the production of determiner + noun phrases (e.g., the cat). More specifically, we ask whether the processing of the two words composing these utterances occurs simultaneously or is separable in time.

German native speakers were asked to name pictures (one per trial) using a determiner and a noun, while ignoring a printed distractor word superimposed on the picture (picture-word interference paradigm). The presence of a distractor allowed us to create independent markers for the processing of the noun and the determiner.

To obtain an index of the processing of the noun, we manipulated the phonological overlap between the target noun and distractor. Previous research has shown that latencies are shorter in trials with phonological overlap. This effect (hereafter the "phonological congruency effect") has been associated with the phonological encoding of the noun (Meyer, 1996; Meyer \& Schriefers, 1991, see also Lupker, 1982; Roelofs, 1997; Schriefers, Meyer, \& Levelt, 1990; Starreveld \& La Heij, 1995, 1996; Starreveld, 2000; for EEG evidence see for instance Dell'Acqua et al., 2010).

To obtain an index of the processing of the determiner, we manipulated the congruency between the gender of the target and that of the distractor. Previous studies have shown that in several languages (including Dutch, or German) latencies were slower with incongruent than with congruent distractors (Heij, Mak, Sander, \& Willeboordse, 1998; Schiller \& Caramazza, 2003; Schriefers, 1993; van Berkum, 1997). This gender congruency effect has been associated with competition between the determiner forms of the target and distractor in behavioural stud- 
ies (see Schiller \& Caramazza, 2003) and in neuroimaging studies (e.g., Heim, Friederici, Schiller, Rüschemeyer, \& Amunts, 2009).

\section{Experiment}

\section{Participants}

Twenty German native speakers (5 men), aged between 18 and 39, took part in the experiment. They were living in France at the time of the experiment. They were all right-handed with no reported hearing or language disorders.

Note that the experiment was conducted in France, and that all speakers were also fluent speakers of French. They had all learned to speak this language in early adulthood (age of arrival in France was 24 years on average, number of months since arrival in the country varied between 11 and 120 months, with a mean of 54 months).

Before the experimental session, the participants were given details about the experimental procedure and they provided their informed consent. The study received appropriate ethical approval (filed under "ID RCB : 2011-A00562-39" at "Comite de Protection des Personnes Sud Méditerranée I"). They were paid 30 euros for their participation.

One participant was discarded due to a high number of eye blinks. Another participant was excluded because her ERPs did not clearly reveal the usual P100 component associated with visual tasks. This left 18 participants to be included in the analysis we report.

\section{Materials}

We selected 70 pictures corresponding to German nouns (i.e., target nouns, see Appendix 1). Half of the nouns had feminine gender and half had masculine gender. We also selected 70 feminine and 70 masculine nouns to be used as distractors. All distractors had between three and ten letters (mean number of letters: 5.8, S.D. $=1.6$ ). Each picture was associated with four distractors. The first two distractors overlapped phonologically with the target noun (one to four of the initial phonemes were identical), the other two did not. Of the two distractors in each condition (overlap and no overlap), one had the same gender as the target noun (gender congruent condition), the other had a different gender than that of the target noun (gender incongruent condition). 
We formed two lists of distractors. The first list was used in gender congruent trials and the second in gender incongruent trials. Distractors in each of these two lists were used twice, once with a phonologically overlapping target and once with a non-overlapping target. The mean number of phonemes shared between the target and distractor words in the phonological overlap condition did not differ between gender congruent (mean $=2.3$ ) and gender incongruent $($ mean $=2.2, p>0.4)$ trials.

Distractors in the two lists were matched on number of letters and syllables, and on lexical frequency as provided by the CELEX database (Baayen, Piepenbrock, \& Gulikers, 1995). Target nouns and the corresponding distractors did not overlap semantically.

We created four experimental lists, each with the 140 target words. In each list, the pictures were paired with a different distractor such that each picture appeared once and in a different condition in each list. Each participant saw the four lists. The order of the lists during the experiment was counterbalanced across participants.

\section{Procedure}

The experiment was run with the E-prime 2.0 software (Psychology Software Tools, Pittsburgh, PA). Participants were tested individually, in a quiet booth, at Aix-Marseille University in Marseille (France). They received instructions in German by a German native speaker.

The experiment started with a familiarization phase. During this phase, the pictures of the experiment appeared on the screen and the participants had to name them in German together with the corresponding definite determiner. A white rectangle showing the characters "XXXX" was superimposed on each picture where the distractor nouns were to be placed during the test phase. After naming a given picture, participants pressed the space bar to see the intended determiner and noun written below the picture. During the test phase, participants had to name the pictures using the definite determiner and corresponding noun while ignoring a printed distractor superimposed on the picture. Each trial started with a fixation cross, followed, after $500 \mathrm{~ms}$, by a $200 \mathrm{~ms}$ blank screen interval. The picture with the superimposed distractor was then presented on the screen for 2300 ms. The next trial started after a 2000 ms blank screen interval. 
Pictures appeared as a black outline on a white square. The position and size of the distractor were identical across conditions but the position of the distractor differed slightly among the pictures (see Miozzo \& Caramazza, 1999).

Every three trials participants saw a picture depicting shut eyes during $2500 \mathrm{~ms}$. They were told to blink when seeing this picture and to avoid blinking at other times. The next trial started after a 700 ms blank screen interval.

As noted above, all participants had French as their second language; during the same experimental session, the also performed the task in French with different materials. Because the French experiment addressed a different issue (i.e., flexibility in encoding strategies in L2), it is not presented here (see Bürki, Sadat, \& Alario, submitted, for more details).

\section{EEG recording and pre-processing}

The EEG was recorded with an Active-Two Biosemi system (BIOSEMI, Amsterdam), using 128 channels. The signal was sampled at $512 \mathrm{~Hz}$. ERP extraction and pre-processing were conducted with the Cartool software (Brunet, Murray, \& Michel, 2011) and EEGLAB Matlab toolbox (Delorme \& Makeig, 2004). Offline, the EEG signals were averaged referenced and band-pass filtered between 0.2 and $30 \mathrm{~Hz}$ ( $2^{\text {nd }}$ order Butterworth filter). We also applied a $50 \mathrm{~Hz}$ notch filter. We did not apply any baseline correction. The time interval between stimulus presentation and the end of the analyzed period was quite large, and this may have resulted in potentially large inter-trial variation (e.g., Luck, 2014), especially in the last part of the time window of interest. Additional arguments against the use of baseline corrections can be found for instance in Michel, Koenig, \& Brandeis (2009).

Epochs corresponding to incorrect naming responses were excluded from further processing. The remaining epochs were visually inspected for artefacts (eye blinks, movements). Epochs with artefacts or amplitudes exceeding $\pm 100 \mu \mathrm{V}$ were rejected. A 3-D spline interpolation was applied to all electrodes with a bad signal (between $3 \%$ and $17 \%$ of electrodes per participant, mean = 12\%). The same interpolation was applied to all the individual epochs of a given participant. Stimulus-locked (from picture onset to 250 time frames [TF] - or $488 \mathrm{~ms}$ ) and response-locked epochs (from $480 \mathrm{~ms}$ to $100 \mathrm{~ms}$ before the onset of the verbal response) were extracted and exported in the EEGLAB format in order to be processed with LIMO (Pernet, Chauveau, Gaspar, \& Rousselet, 2011). Several studies have indeed shown that response related processes (e.g., pho- 
nological encoding processes) can be examined by aligning the EEG averages on the onset of the vocal responses (see for instance Laganaro, 2014; Riès, Janssen, Burle, \& Alario, 2013).

Response-locked analyses capture activities and effects whose timing is locked to the response and are especially appropriate when the late effects are targeted. Response times in naming tasks vary greatly among items and participants. The further away we move from the point of alignment, the greater the variability among trials and the lesser the chance to capture an effect. Moreover, given that the window of analysis is set to equal the duration of the shortest trial a stimulus locked analysis alone contains no information on the late encoding processes for most of the trials, similarly a response-locked analysis alone contains no information on the early processes for these same trials.

\section{Analyses and results}

Naming responses

Responses and naming latencies (i.e., time interval between picture onset and articulation onset) were manually checked offline for accuracy with the software Praat (Boersma \& Weenink, 2014). Within the 5040 trials recorded, there were 237 errors (5\%), most of them due to dysfluencies (73\% of the errors) or to the use of a noun other than the intended one (15\%). Among the remaining errors, $10 \%$ involved the wrong determiner, and $2 \%$ were missing responses or mispronunciations. Five items (0.001\%) had unclear voice onsets and were removed. Visual inspection of the distribution of naming latencies led to the removal of 36 data points $(0.7 \%)$ below $580 \mathrm{~ms}$. The item "Schaufel" (shovel) was removed from further analyses because of extremely high mean naming latencies $(1018 \mathrm{~ms})$ compared to the other items. The dataset was further restricted to the 3762 trials (75\% of trials) with EEG uncontaminated epochs.

We analysed naming latencies with mixed-effects regression models (e.g., Baayen, Davidson, \& Bates, 2008; Goldstein, 1987) using the statistical software R (R Development Core Team, 2014) and library LmerTest (Kuznetsova, 2014). Order of presentation, gender congruency and phonological overlap were entered in the models as fixed effects. The model had random intercepts for participants and items, and random slopes allowing for the effects of gender congruency and phonological overlap to differ across participants and items (see for instance Baayen \& Milin, 2010; Barr, Levy, Scheepers, \& Tily, 2013). To ensure that the results were not 
driven by few atypical data points, residuals larger than 2.5 times the standard deviation were considered outliers and removed (Baayen, 2008). Following the results of the Box-Cox test (Box \& Cox, 1964), we used the inverse of the latencies as the dependent variable. Denominator degrees of freedom and $p$-values were computed based on Satterthwaite's approximations.

Responses to gender congruent trials were initiated with shorter naming latencies than responses to gender incongruent trials $(777 \mathrm{~ms}$ and $819 \mathrm{~ms}$ respectively, SE of the difference between means $=5.7 \mathrm{~ms}$ ). Responses in the phonological overlap condition were initiated with shorter naming latencies than responses in the no overlap condition $(789 \mathrm{~ms}$ and $806 \mathrm{~ms}$ respectively, SE of the difference between means $=5.7 \mathrm{~ms})$. The statistical model revealed significant fixed effects of gender congruency $\left(F(1,329.1)=14.1, p<0.001 ; \beta=1.6 \times 10^{-05}\right.$, SE $=$ $\left.4.3 \times 10^{-06}, t=3.8, p<0.001\right)$ and of phonological overlap $(F(1,26.3)=57.1, p<0.0001 ; \beta=5.1 \times$ $\left.10^{-05}, \mathrm{SE}=6.7 \times 10^{-06}, t=7.6, \mathrm{p}<0.0001\right)$. We note that naming latencies also decreased with order of presentation $\left(F(1,5852.2)=859.3 ; \beta=-7.5 \times 10^{-07}, t=-29.3, \mathrm{SE}=2.6 \times 10^{-07}, p<0.0001\right)$. ERP

Stimulus-locked (from picture onset to $380 \mathrm{~ms}$ ) and response-locked (from $480 \mathrm{~ms}$ to $100 \mathrm{~ms}$ before the onset of articulation) single trial ERPs were analysed over all space and time dimensions using a hierarchical general linear model, following the procedure described in Pernet et al. (2011). In LIMO, the data of each participant were first analysed separately to estimate the parameters of the General Linear Model based on information at each time point and electrode. These estimated parameters were then used to test for statistical significance across participants with robust parametric tests. We highlight that this analysis is performed without any a priori restriction over time or spatial localisation of the effects (e.g., a priori timewindows or sets of electrodes).

We examined the effects of two categorical predictors, gender congruency and phonological overlap, and of one covariate, the position of the trial within the experimental session (i.e., order of presentation). The effects of the two categorical predictors were assessed with robust paired t-tests, the effect of the covariate was assessed with a one sample t-test (see Pernet et al., 2011, for a detailed account of the exact statistical procedures we followed). Each of these analyses was performed using 1000 bootstraps. Corrections for multiple comparisons were applied using spatio-temporal clustering (Maris \& Oostenveld, 2007, see also Pernet et al., 2011) 
with alpha set to 0.05 . In addition, an effect at a given electrode was only considered significant when it lasted for at least 5 time frames (i.e., $10 \mathrm{~ms}$ ).

Figure 1 shows the stimulus-locked grand-averaged ERPs at selected electrodes, and corresponding topographies. The N1/P2 components were clearly visible and were followed by a broader component, as is typically observed in stimulus-locked activity for the picture naming task (e.g., Laganaro, 2014; Llorens, Trébuchon, Riès, Liégeois-Chauvel, \& Alario, 2014).

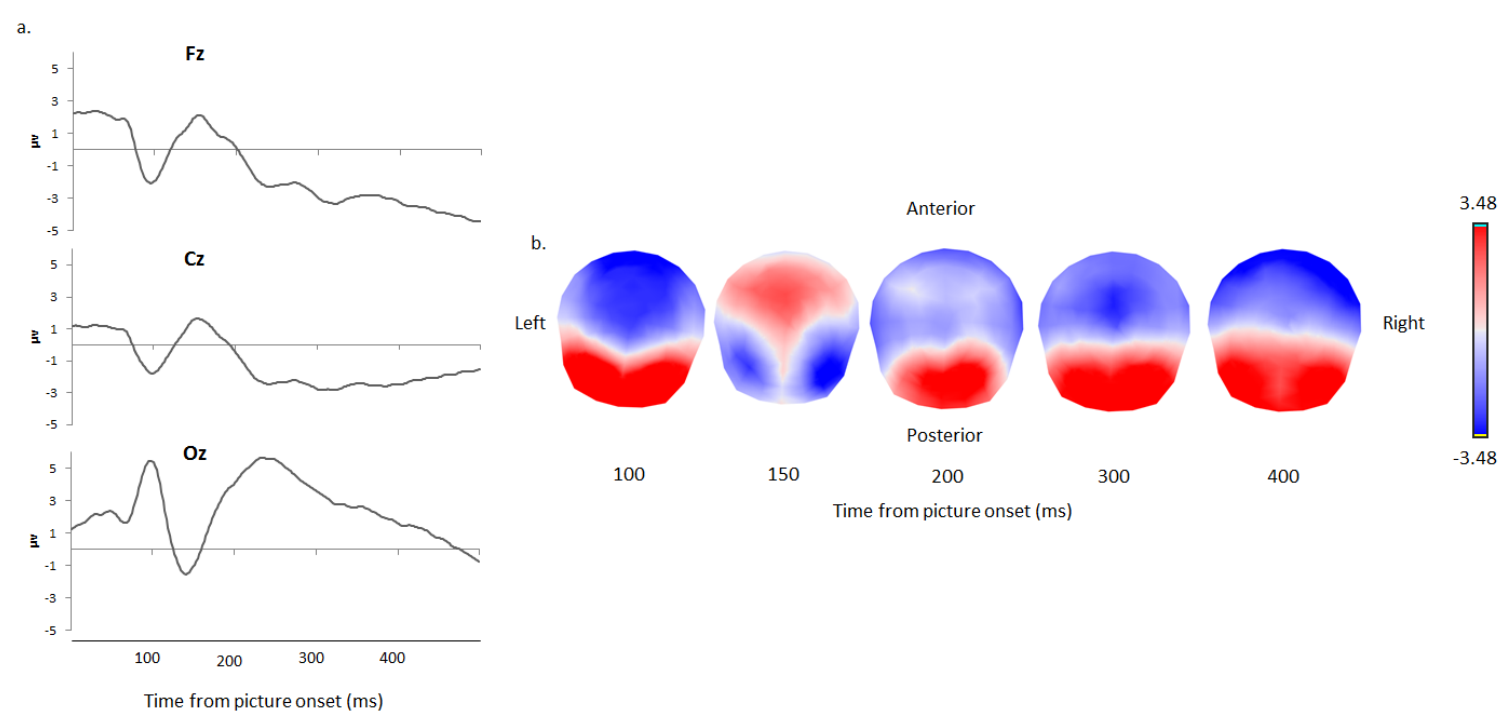

Fig 1. Stimulus locked ERPs averaged across all participants and conditions with: a. Waveform at selected electrodes and $b$. Topographies at different time windows

The analysis of the stimulus-locked ERPs revealed no significant differences across the experimental conditions for either the phonological or the gender manipulations (see Figure 2). In contrast, both manipulations showed effects in the response-locked ERPs. Figure 2 and 3 show the results of the robust paired t-tests on amplitudes for the stimulus-locked and responselocked ERPs, respectively, for the phonological and gender manipulations. 
a.
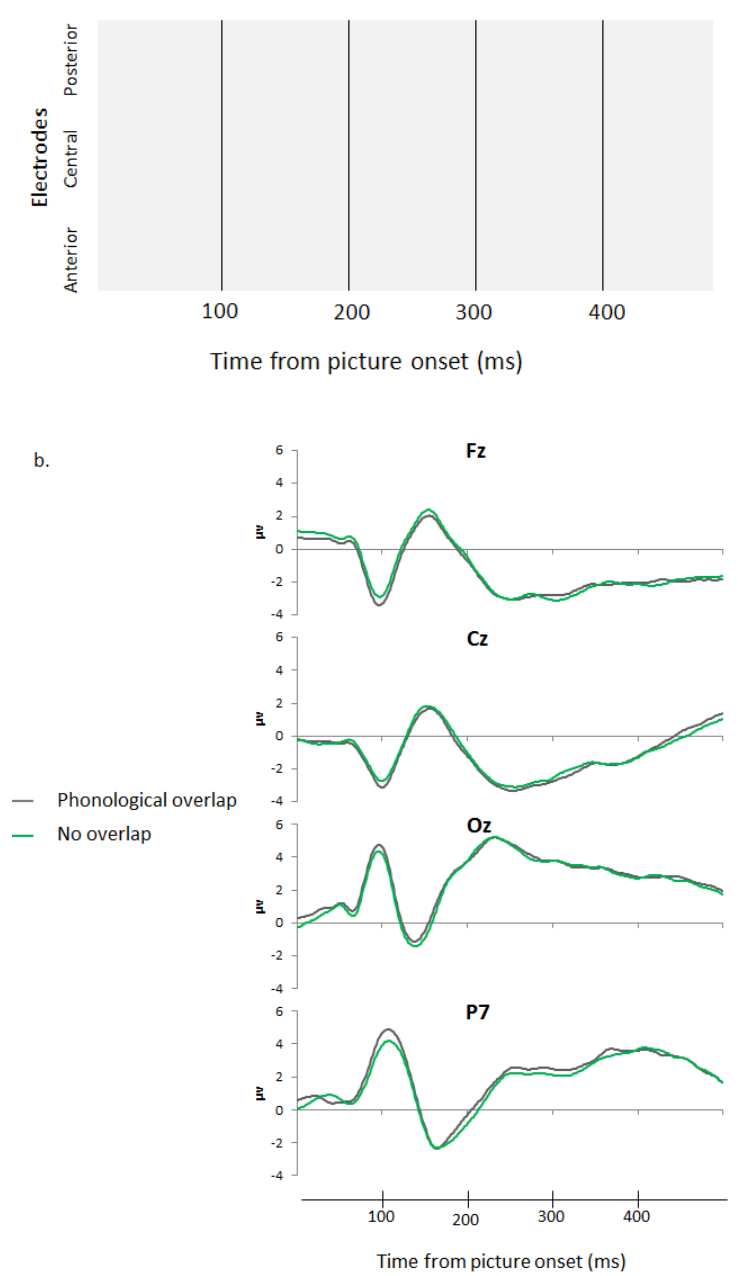
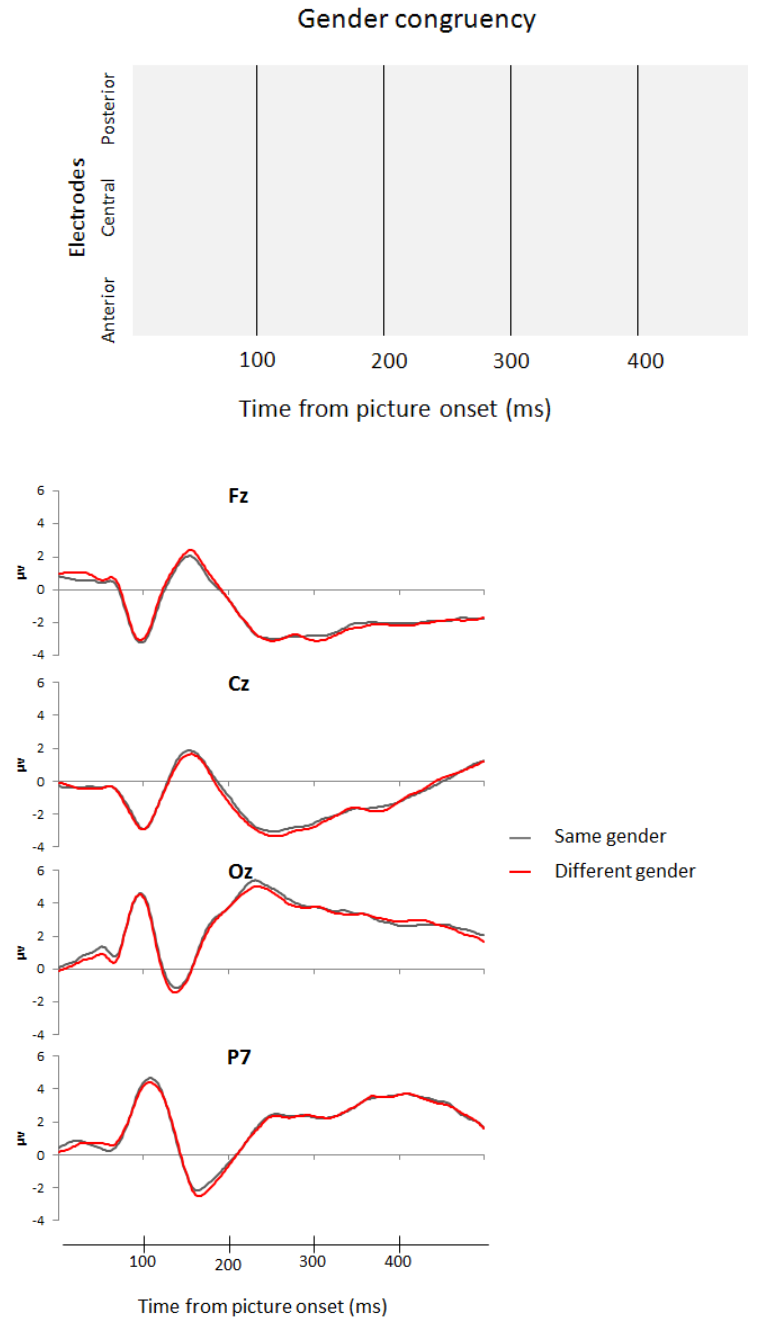

Figure 2: $a$. Results of robust paired t-tests (representation of significant t-values) for phonological overlap (left) and gender congruency (right) after correction for multiple comparisons; each line is an electrode. $b$. Mean waveforms for the different conditions at selected electrodes 

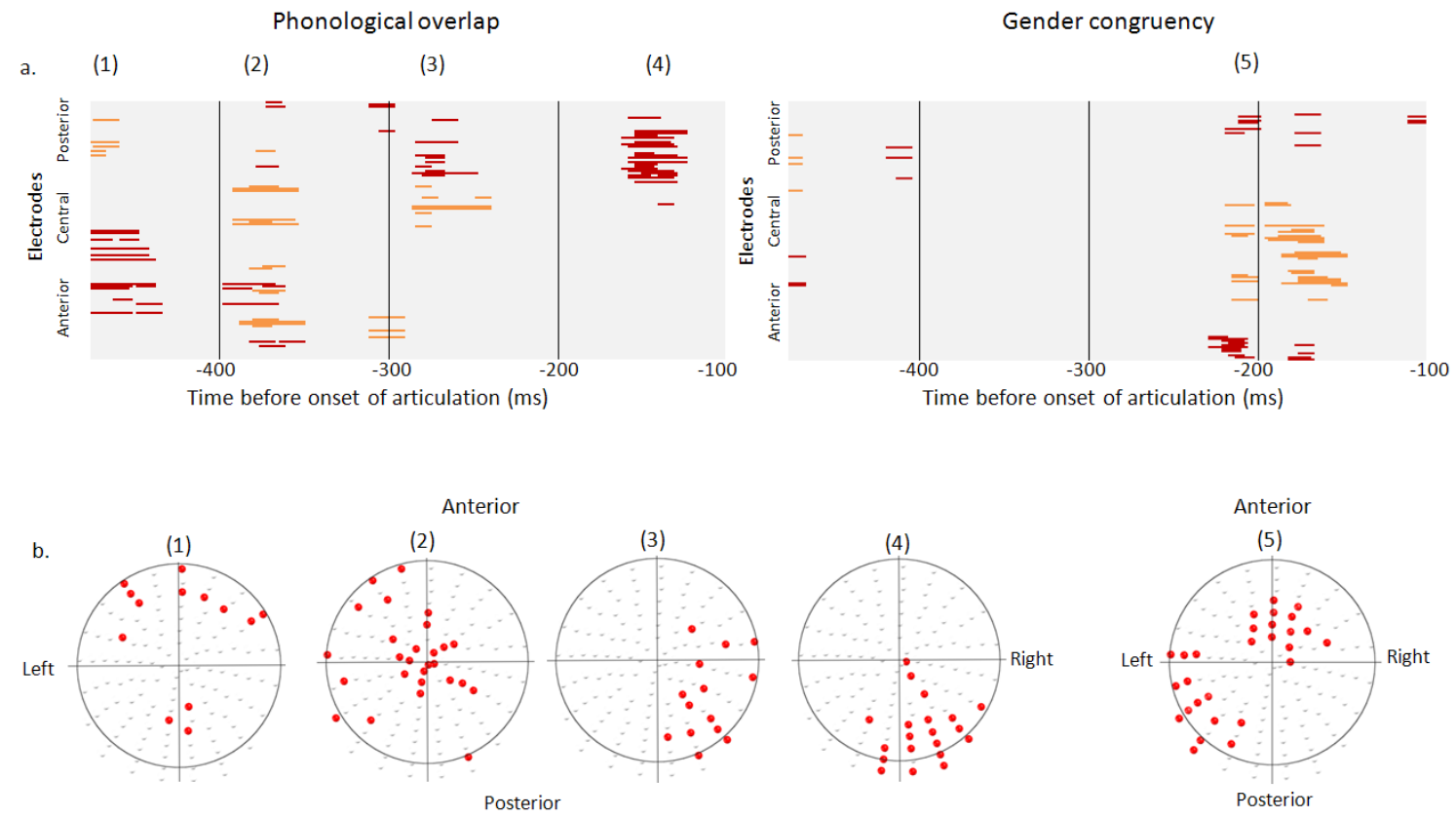

Figure 3: $a$. Results of robust paired t-tests (representation of significant $t$-values) for phonological congruency (left) and gender congruency (right) after correction for multiple comparisons; with the colours representing electrodes with higher (red) and lower (orange) amplitudes for trials with phonological or gender congruent trials; each line is an electrode. $b$. Schematic of the electrodes with significant differences at different time-windows. c. Mean waveforms for the different conditions at selected electrodes; note that the shape of the ERPs is typical of response-locked analyses in speech production tasks (e.g., Laganaro, 2014).

As can be seen on the left-hand side of Figure 3, amplitudes differ as a function of phonological overlap at several time windows. The earliest difference (1) starts $480 \mathrm{~ms}$ before the onset of articulation and lasts for about 50 to $60 \mathrm{~ms}$. The second difference (2) lasts from about 390 to $350 \mathrm{~ms}$ before the onset of articulation. A third time period (3) affected by the phonological overlap between target and distractor starts about $280 \mathrm{~ms}$ before the onset of articulation and lasts for about $20 \mathrm{~ms}$. Finally, there is a late effect of phonological overlap (4), from about 165 to 130 before the onset of articulation. The difference in amplitudes between gender-congruent 
and gender-incongruent trials is much less widespread in time. It starts about $210 \mathrm{~ms}$ before the onset of articulation and lasts for about $60 \mathrm{~ms}$. Notably, the two effects do not overlap in time.

\section{General Discussion}

Using EEG, we tested the extent to which empirical effects associated with noun and determiner processing overlap in time and space during the preparation of noun phrase utterances. Behavioural results replicated both the phonology ${ }^{1}$ and the gender congruency effects (e.g., Meyer \& Schriefers, 1991; Schriefers, 1993). In addition, the phonological and gender manipulations affected the EEG data. Crucially, the two effects occurred in different time windows over different sets of electrodes (i.e., over non-overlapping topographies). This finding is as predicted if the processing of two words in determiner noun phrases occurs at least partly sequentially.

In the remainder of the discussion we interpret the present findings in the light of prior data and hypotheses regarding the source of the phonological and gender congruency effects. Doing so allows explicit proposals regarding the temporal alignment of underlying encoding processes in multi-word noun phrase production.

Empirical evidence from previous studies suggests that both the phonological congruency and gender congruency effects occur during the phonological processing of the utterance. The phonological congruency effect has been associated with various cognitive sub-processes involved in phonological encoding, i.e., lexeme access, the activation of the individual phonemes of the word, and the insertion of the phonemes in the metrical frame (metrical spell-out, Levelt, Roelofs, \& Meyer, 1999). The gender congruency effect has been associated with competition between the determiner forms of the target and distractor (Heim et al., 2009; Schiller \& Caramazza, 2003). Under the assumption that the ERP and behavioral effects we observe in the present study have a common origin (more on this below), the time course of the gender and phonological congruency effects reveal that the phonological encoding of the determiner and that of the noun occur sequentially. In addition, this time course suggests that accessing to

\footnotetext{
${ }^{1}$ The effect of phonological congruency may appear relatively small $(17 \mathrm{~ms})$ in the present study when compared to similar effects reported in previous studies (e.g., > 30 ms in Meyer \& Schriefers, 1991, with auditory distractors, or in Dell'acqua et al., 2010 with written distractors). This may be due to a smaller number of overlapping phonemes in the present study, with some target-disctractor pairs overlapping in only one phoneme.
} 
noun's word form (as indexed by the onset of the phonological facilitation effect) occurs prior to accessing the determiner's word form (as indexed by the gender congruency effect).

The idea that the determiner word form is accessed after the noun word form is not new. Previous research led to the formulation of the "early" and "late-selection" hypotheses for determiner selection (Caramazza, Miozzo, Costa, Schiller, \& Alario, 2001; Costa, Alario, \& Sebastián-Gallés, 2007). These hypotheses state that determiner selection will occur "relatively early" in the response preparation process when selection is mostly guided by grammatical gender (e.g., in several Germanic languages), and that it will occur "relatively late" when grammatical gender and phonology fully determine the determiner form (as in several Romance languages $\left.{ }^{2}\right)$. This proposal was solely based on response time data. The present study shows that even in languages with reputedly "early determiner selection" (e.g., German), where the form of the determiner does not strictly depend on the noun's phonology, determiner form processing is detected significantly later than noun form processing.

Up to this point we have interpreted the ERP effects solely in the context of earlier interpretations of behavioural findings. Yet, ERPs can potentially reveal richer and more subtle differences in processing than response times do and could reflect other/additional processes. We note for instance that the phonological congruency effect is mostly observed before the gender congruency effect, but that it also shows a later component. We speculate that the later "rebound" of the effect might reflect metrical spell-out or a pre-response monitoring process in relation to the insertion of the determiner form in the metrical phrase ${ }^{3}$. The suggestion that the different temporal occurrences of a phonological effect in the EEG data may reflect different underlying processes echoes back to a proposal by Schuhmann, Schiller, Goebel, and Sack (2012). The authors used TMS to determine the functional relevance and time course of the left posterior inferior frontal gyrus (IFG), left middle temporal gyrus (MTG) and left posterior superior temporal gyrus (STG) during a picture naming task. They observed that the MTG is

\footnotetext{
${ }^{2}$ In these languages (as well as in English) the form of the determiner may be determined by the phonology of the noun (e.g., le chien 'the dog' vs. l'âne 'the donkey' in French). Studies have reported that in these languages, speakers are not sensitive to the congruency in gender between target and distractor (e.g., Alario \& Caramazza, 2002, see also Costa et al., 2007, for a review). Caramazza and colleagues (e.g., Caramazza et al., 2001) suggested that the gender congruency effect is absent precisely because the selection of the form of the determiner is delayed until the properties of the noun are made available. ${ }^{3}$ This could occur, for instance, for the need of resyllabification processes. Resyllabification is indeed required in some contexts, for instance, when the determiner ends with a consonant (e.g., der 'the') and the noun starts with a vowel (e.g., Arm 'arm').
} 
involved $225 \mathrm{~ms}$ after picture onset, the IFG at around $300 \mathrm{~ms}$, and the MTG again around 400 together with the posterior STG. The authors assume that the early involvement of the MTG reflects lexical retrieval, that the involvement of the IFG at $300 \mathrm{~ms}$ reflects phonological encoding processes, and that the late effects reflect monitoring processes.

Similarly the question may arise of whether the ERP manifestation of the gender congruency effect could reflect a late monitoring process, in which the appropriateness of the determiner form is checked. Distinguishing between cognitive processes and the monitoring of these processes on empirical grounds is not straightforward without an ad-hoc manipulation, as any ERP effect can probably be argued to reflect one, the other or both. Crucially for our purposes, an account of the late occurring gender and phonology effects in terms of monitoring would not alter the key conclusion of the present study, i.e., that the determiner and noun are processes with some amount of sequentiality. In addition, we note that that the monitoring account would implies that ERP and response time effects have a different source. As such, it is arguably less parsimonious than a single locus account. The locus of the gender congruency effect in response times has been examined in several studies, and these studies all converge on the conclusion that the effect arises because the determiner form from the distractor competes with the determiner to be produced.

Another relevant issue concerns the extent to which the time course of the ERP effects also reflects the time course of encoding of the distractor word. In the picture word interference paradigm, effects emerge as a consequence of the relationship between the target and distractor words. They thus provide information on the processing of both words. In this context, the question may arise of whether the time course of the phonological and gender congruency effects could reflect the time course of processing of the distractor. It could be argued for instance that the phonological information of the distractor is accessed before the information about its gender. The retrieval of the target word would be facilitated by the amount of overlapping information in a first step and by the overlap in gender in a second step. First note that in this account, the ERP and response time effects have a different locus. In addition, this account assumes that the phonological encoding of the target word precedes the grammatical encoding of this word, in contradiction with the widely held assumption that speakers access the grammatical features of the words prior to their phonological content (e.g., van Turennout, Hagoort, \& Brown, 1998 for admittedly debated empirical evidence). More importantly, in the 
present study, the effects are observed when the ERP is time-locked to the production of the target sequence, not on the presentation of the distractor word. Compared to a stimulus-locked analysis, the response locked analysis blurs the potentials evoked by stimulus processing and highlights the activity synchronized to response preparation (Riès et al., 2013). For this reason, the influence of the distractor word on the ERP signal should primarily reveal the encoding of the target word at every particular time point. Irrespective of when the phonological information from the distractor word is processed, this phonological information should not affect the processing of the target word unless the target word is being phonologically encoded at this particular time point. The finding that the gender congruency effect occurs after the phonological congruency effect in the EEG can thus not readily be interpreted as reflecting solely the time course of encoding of the distractor word.

So far we have discussed the relative time course of the two effects. Their actual timing does not inform us on the onset or offset of the phonological encoding of the target word, but points to time windows in which the phonological information of the target word is being processed. This timing appears congruent with previous evaluations of the time course of phonological encoding estimated in bare noun production studies. In the present study, the phonological congruency effect becomes apparent in a time window around $480 \mathrm{~ms}$ before the onset of articulation (or counting forward from the stimulus, about $300 \mathrm{~ms}$ after picture onset). This timing is consistent with the findings of a previous EEG study of the same paradigm. Using a jacknife procedure, the data in Dell'Acqua et al. (2010) revealed a phonological congruency effect in the picture word interference paradigm at about 320 ms after picture onset (for mean naming latencies of about $870 \mathrm{~ms}$ ). Unlike in the present study, this effect was apparent in the stimulus-locked ERPs (but see Blackford, Holcomb, Grainger, \& Kuperberg, 2012 for an absence of difference between phonologically related and phonologically unrelated masked primes in the stimulus-locked ERPs, despite an advantage for phonologically related trials in the response times). More generally, according to Indefrey (2011)'s meta-analysis (Indefrey \& Levelt, 2004 and Strijkers \& Costa, 2011 for a critical standpoint), word form access starts $275 \mathrm{~ms}$ after picture onset for a mean response time of $600 \mathrm{~ms}$ (i.e., $325 \mathrm{~ms}$ before the onset of articulation) and the insertion of phonemes in the metrical frame (segmental spell-out) lasts from 355 to $465 \mathrm{~ms}$ after picture onset (i.e., 245 to $135 \mathrm{~ms}$ before the onset of articulation). The phonological congruency effect we observed for the noun (once again, about 300 ms after picture onset) broadly occurs in a similar time window. Interestingly, ERP differences were observed in the response-locked but not in the stimulus- 
locked analysis. Response-locked analyses capture activities and effects whose timing is locked to the response. The fact that we observe robust effects in the response-locked analysis and no effect in the stimulus-locked analysis suggests that the phonological and gender congruency effects are better locked to the initiation of the vocal response than to the visual processing of the stimulus.

To conclude, neurolinguistic studies of word production have started to provide increasingly detailed information on the time course of cognitive mechanisms underlying the production of isolated words. A major challenge for neurolinguistic research today is to extend this study to multi-word utterances, such as determiner noun phrases, or natural speech. The present work provides crucial information on this issue by showing substantially sequential processes during the production of determiner noun phrases.

\section{Acknowledgements}

We acknowledge funding from the Swiss National Science Foundation (grant n`IZK0Z1-146008), the University of Geneva (Subside tremplin), the European Research Council under the European Community's Seventh Framework Program (FP7/2007-2013 Grant agreement n॰263575), and the Brain and Language Research Institute (Aix-Marseille Université : A*MIDEX grant ANR-11IDEX-0001-02 and LABEX grant ANR-11-LABX-0036). We thank the "Féderation de Recherche 3C" (Aix-Marseille Université) for institutional support.

\section{References}

Alario, F.-X., \& Caramazza, A. (2002). The production of determiners: Evidence from French. Cognition, 82(3), 179-223. doi:10.1016/S0010-0277(01)00158-5

Alario, F.-X., Costa, A., \& Caramazza, A. (2002a). Frequency effects in noun phrase production: Implications for models of lexical access. Language and Cognitive Processes, 17(3), 299-319. doi:10.1080/01690960143000236

Alario, F.-X., Costa, A., \& Caramazza, A. (2002b). Hedging one's bets too much? A reply to Levelt (2002). Language and Cognitive Processes, 17(6), 673-682. doi:10.1080/01690960143000461 
Allum, P. H., \& Wheeldon, L. R. (2007). Planning scope in spoken sentence production: The role of grammatical units. Journal of Experimental Psychology: Learning, Memory, and Cognition, 33(4), 791-810. doi:10.1037/0278-7393.33.4.791

Baayen, R. H. (2008). Analyzing linguistic data: A practical introduction to statistics using $R$. New York: Cambridge University Press.

Baayen, R. H., Davidson, D. J., \& Bates, D. M. (2008). Mixed-effects modeling with crossed random effects for subjects and items. Journal of Memory and Language, 59(4), 390-412. doi:10.1016/j.jml.2007.12.005

Baayen, R. H., \& Milin, P. (2010). Analyzing reaction times. International Journal of Psychological Research, $3(2), 12-28$.

Baayen, R. H., Piepenbrock, R., \& Gulikers, L. (1995). CELEX2 LDC96L14. Philadelphia: Linguistic Data Consortium.

Barr, D. J., Levy, R., Scheepers, C., \& Tily, H. J. (2013). Random effects structure for confirmatory hypothesis testing: Keep it maximal. Journal of Memory and Language, 68(3), 255-278. doi:10.1016/j.jml.2012.11.001

Blackford, T., Holcomb, P. J., Grainger, J., \& Kuperberg, G. R. (2012). A funny thing happened on the way to articulation: N400 attenuation despite behavioral interference in picture naming. Cognition, 123(1), 84-99. doi:10.1016/j.cognition.2011.12.007

Bock, K. (1987). Exploring levels of processing in sentence production. In G. Kempen (Ed.), Natural Language Generation (pp. 351-363). Boston: Martinus Nijhoff Publishers

Boersma, P., \& Weenink, D. (2014). Praat: Doing phonetics by computer (Version 5.4.01).

Box, G. E. P., \& Cox, D. R. (1964). An analysis of transformations. Journal of the Royal Statistical Society. Series B (Methodological), 26(2), 211-252.

Brunet, D., Murray, M. M., \& Michel, C. M. (2011). Spatiotemporal analysis of multichannel EEG: CARTOOL. Computational Intelligence and Neuroscience, 2011, e813870. doi:10.1155/2011/813870 
Bürki, A., \& Laganaro, M. (2014). Tracking the time course of multi-word noun phrase production with ERPs or on when (and why) cat is faster than the big cat. Language Sciences, 5, 586. doi:10.3389/fpsyg.2014.00586

Bürki, A., Sadat, J., \& Alario, F.-X. (submitted). Time course of phonological encoding in proficient bilinguals.

Caramazza, A., Miozzo, M., Costa, A., Schiller, N. O., \& Alario, F.-X. (2001). A crosslinguistic investigation of determiner production. In E. Dupoux (Ed.), Language, Brain and Cognitive Development: Essays in Honor of Jacques Mehler (pp. 209-226). Cambridge, MA: MIT Press.

Costa, A., Alario, F.-X., \& Sebastián-Gallés, N. (2007). Cross-linguistic research on language production. In M. G. Gaskell (Ed.), The Oxford Handbook of Psycholinguistics (pp. 531-546). Oxford: Oxford University Press.

Costa, A., Navarette, E., \& Alario, F.-X. (2006). Accessing object names when producing complex noun phrases: Implications for models of lexical access. Cognitiva, 18 (1), 3-23. doi: $10.1174 / 021435506775462454$

Damian, M. F., \& Dumay, N. (2009). Exploring phonological encoding through repeated segments. Language and Cognitive Processes, 24(5), 685-712. doi:10.1080/01690960802351260

Dell'Acqua, R., Sessa, P., Peressotti, F., Mulatti, C., Navarrete, E., \& Grainger, J. (2010). ERP Evidence for ultra-fast semantic processing in the picture-word interference paradigm. Frontiers in Psychology, 1, 177. doi:10.3389/fpsyg.2010.00177

Dell, G. S. (1986). A spreading-activation theory of retrieval in sentence production. Psychological Review, 93(3), 283-321. doi: 10.1037/0033-295X.93.3.283

Delorme, A., \& Makeig, S. (2004). EEGLAB: An open source toolbox for analysis of single-trial EEG dynamics including independent component analysis. Journal of Neuroscience Methods, 134(1), 9-21. doi:10.1016/j.jneumeth.2003.10.009

Eulitz, C., Hauk, O., \& Cohen, R. (2000). Electroencephalographic activity over temporal brain areas during phonological encoding in picture naming. Clinical Neurophysiology, 111(11), 2088-2097. doi:10.1016/S1388-2457(00)00441-7 
Ganushchak, L. Y., Christoffels, I. K., \& Schiller, N. O. (2011). The use of Electroencephalography in language production research: A Review. Frontiers in Psychology, 2, 208. doi:10.3389/fpsyg.2011.00208

Garrett, M.-F. (1975). The analysis of sentence production. In G. Bower (Ed.), Psychology of learning and motivation (p. 133-177). New York: Academic Press.

Goldstein, H. (1987). Multilevel models in educational and social research. London: Griffin.

Heij, W. L., Mak, P., Sander, J., \& Willeboordse, E. (1998). The gender-congruency effect in picture-word tasks. Psychological Research, 61(3), 209-219. doi:10.1007/s004260050026

Heim, S., Friederici, A. D., Schiller, N. O., Rüschemeyer, S.-A., \& Amunts, K. (2009). The determiner congruency effect in language production investigated with functional MRI. Human Brain Mapping, 30(3), 928-940. http://doi.org/10.1002/hbm.20556

Indefrey, P. (2011). The spatial and temporal signatures of word production components: A critical update. Language Sciences, 2, 255. doi:10.3389/fpsyg.2011.00255

Indefrey, P., \& Levelt, W. J. M. (2004). The spatial and temporal signatures of word production components. Cognition, 92(1-2), 101-144. doi:10.1016/j.cognition.2002.06.001

Kempen, G., \& Huijbers, P. (1983). The lexicalization process in sentence production and naming: Indirect election of words. Cognition, 14(2), 185-209. doi:10.1016/0010-0277(83)90029-X

Koester, D., \& Schiller, N. O. (2008). Morphological priming in overt language production: electrophysiological evidence from Dutch. Neurolmage, 42(4), 1622-1630. http://doi.org/10.1016/j.neuroimage.2008.06.043

Konopka, A. E. (2012). Planning ahead: How recent experience with structures and words changes the scope of linguistic planning. Journal of Memory and Language, 66(1), 143-162. doi:10.1016/j.jml.2011.08.003

Kuznetsova, A. (2014). Package " ImerTest »: Tests for random and fixed effects for linear mixed effect models (Imer objects of Ime4 package).

Laganaro, M. (2014). ERP topographic analyses from concept to articulation in word production studies. Frontiers in Psychology, 5, 493. doi:10.3389/fpsyg.2014.00493 
Lee, E.-K., Brown-Schmidt, S., \& Watson, D. G. (2013). Ways of looking ahead: Hierarchical planning in language production. Cognition, 129(3), 544-562. doi:10.1016/j.cognition.2013.08.007

Levelt, W. J. M. (2002). Picture naming and word frequency: Comments on Alario, Costa and Caramazza. Language and Cognitive Processes, 17(3), 299-319. doi: 10.1080/01690960143000443

Levelt, W. J. M., Roelofs, A., \& Meyer, A. S. (1999). A theory of lexical access in speech production. The Behavioral and Brain Sciences, 22(1), 1-38. doi:10.1017/S0140525X99001776

Llorens, A., Trébuchon, A., Liegeois-Chauvel, C., \& Alario, F.-X. (2011). Intra-cranial recordings of brain activity during language production. Language Sciences, 2, 375. doi:10.3389/fpsyg.2011.00375

Llorens, A., Trébuchon, A., Riès, S., Liégeois-Chauvel, C., \& Alario, F.-X. (2014). How familiarization and repetition modulate the picture naming network. Brain and Language, 133, 47-58. doi:10.1016/j.bandl.2014.03.010

Lupker, S. J. (1982). The role of phonetic and orthographic similarity in picture-word interference. Canadian Journal of Psychology, 36(3), 349-367. doi: 10.1037/h0080652

Maris, E., \& Oostenveld, R. (2007). Nonparametric statistical testing of EEG- and MEG-data. Journal of Neuroscience Methods, 164(1), 177-190. doi:10.1016/j.jneumeth.2007.03.024

Martin, R. C., Crowther, J. E., Knight, M., Tamborello, F. P., \& Yang, C.-L. (2010). Planning in sentence production: Evidence for the phrase as a default planning scope. Cognition, 116(2), 177-192. doi:10.1016/j.cognition.2010.04.010

Meyer, A. S. (1996). Lexical access in phrase and sentence production: Results from picture-word interference experiments. Journal of Memory and Language, 35(4), 477-496. doi:10.1006/jmla.1996.0026

Meyer, A. S., \& Schriefers, H. (1991). Phonological facilitation in picture-word interference experiments: Effects of stimulus onset asynchrony and types of interfering stimuli. Journal of Experimental Psychology: Learning, Memory, and Cognition, 17(6), 1146-1160. doi:10.1037/02787393.17.6.1146 
Michel, C.M., Koenig, T; \& Brandeis, D. (2009). Electrical neuroimaging in the time domain. In Michel C. M., Koenig, T., Brandeis, D., Gianotti, L. R. R., \& Wackermann, J. (Eds.), Electrical Neuroimaging. Cambridge: Cambridge University Press (pp. 111-144).

Miozzo, M., \& Caramazza, A. (1999). The selection of lexical-syntactic features in noun phrase production: Evidence from the picture-word interference paradigm. Journal of Experimental Psychology: Learning Memory and Cognition, 25, 907-922.

Oppermann, F., Jescheniak, J. D., \& Schriefers, H. (2010). Phonological advance planning in sentence production. Journal of Memory and Language, 63(4), 526-540. doi:10.1016/j.jml.2010.07.004

Pernet, C. R., Chauveau, N., Gaspar, C., \& Rousselet, G. A. (2011). LIMO EEG: A Toolbox for Hierarchical LInear MOdeling of ElectroEncephaloGraphic Data. Computational Intelligence and Neuroscience, 2011, e831409. doi:10.1155/2011/831409

Pylkkänen, L., Bemis, D. K., \& Blanco Elorrieta, E. (2014). Building phrases in language production: An MEG study of simple composition. Cognition, 133(2), 371-384. doi:10.1016/j.cognition.2014.07.001

R core team. (2014). R: A language and environment for statistical computing. Vienna, Austria: R Foundation for Statistical Computing. Retrieved from http://www.R-project.org

Riès, S., Janssen, N., Burle, B., \& Alario, F.-X. (2013). Response-locked brain dynamics of word production. PLoS ONE, 8(3), e58197. doi:10.1371/journal.pone.0058197

Roelofs, A. (1997). The WEAVER model of word-form encoding in speech production. Cognition, 64(3), 249-284. doi: 10.1016/S0010-0277(97)00027-9

Schiller, N. O., \& Caramazza, A. (2003). Grammatical feature selection in noun phrase production: Evidence from German and Dutch. Journal of Memory and Language, 48(1), 169-194. doi:10.1016/S0749$596 \times(02) 00508-9$

Schuhmann, T., Schiller, N. O., Goebel, R., \& Sack, A. T. (2011). Speaking of Which: Dissecting the Neurocognitive Network of Language Production in Picture Naming. Cerebral Cortex, bhr155. http://doi.org/10.1093/cercor/bhr155

Schnur, T. T., Costa, A., \& Caramazza, A. (2006). Planning at the phonological level during sentence 
production. Journal of Psycholinguistic Research, 35(2), 189-213. doi:10.1007/s10936-005-90116

Schriefers, H. (1992). Lexical access in the production of noun phrases. Cognition, 45(1), 33-54. http://doi.org/10.1016/0010-0277(92)90022-A

Schriefers, H. (1993). Syntactic processes in the production of noun phrases. Journal of Experimental Psychology: Learning, Memory, and Cognition, 19(4), 841-850.

Schriefers, H., Meyer, A. S., \& Levelt, W. J. M. (1990). Exploring the time course of lexical access in language production: Picture-word interference studies. Journal of Memory and Language, 29(1), 86-102. doi:10.1016/0749-596X(90)90011-N

Schriefers, H., de Ruijter, J., \& Steigerwald, M. (1999). Parallelism in the production of noun phrases: Experiments and reaction time models. Journal of Experimental Psychology: Learning, Memory, and Cognition, 25(3), 702-720. doi:10.1037/0278-7393.25.3.702

Smith, M., \& Wheeldon, L. (1999). High level processing scope in spoken sentence production. Cognition, 73(3), 205-246. doi:10.1016/S0010-0277(99)00053-0

Starreveld, P. A. (2000). On the interpretation of onsets of auditory context effects in word production. Journal of Memory and Language, 42(4), 497-525. doi:10.1006/jmla.1999.2693

Starreveld, P. A., \& La Heij, W. (1995). Semantic interference, orthographic facilitation, and their interaction in naming tasks. Journal of Experimental Psychology: Learning, Memory, and Cognition, 21(3), 686-698. doi:10.1037/0278-7393.21.3.686

Starreveld, P. A., \& La Heij, W. (1996). The locus of orthographic-phonological facilitation: Reply to Roelofs, Meyer, and Levelt (1996). Journal of Experimental Psychology: Learning, Memory, and Cognition, 22(1), 252-255. doi:10.1037/0278-7393.22.1.252

Strijkers, K., \& Costa, A. (2011). Riding the lexical speedway: A critical review on the time course of lexical selection in speech production. Frontiers in Psychology, 2, 356. doi:10.3389/fpsyg.2011.00356

Townsend, J. T., \& Wenger, M. J. (2004). The serial-parallel dilemma: A case study in a linkage of theory and method. Psychonomic Bulletin \& Review, 11(3), 391-418. doi:10.3758/BF03196588 
Van Berkum, J. J. A. (1997). Syntactic processes in speech production: The retrieval of grammatical gender. Cognition, 64(2), 115-152. doi:10.1016/S0010-0277(97)00026-7

Turennout, M. van, Hagoort, P., \& Brown, C. M. (1998). Brain Activity During Speaking: From Syntax to Phonology in 40 Milliseconds. Science, 280(5363), 572-574.

http://doi.org/10.1126/science.280.5363.572

Wheeldon, L., Ohlson, N., Ashby, A., \& Gator, S. (2013). Lexical availability and grammatical encoding scope during spoken sentence production. Quarterly Journal of Experimental Psychology, 66(8), 1653-1673. doi:10.1080/17470218.2012.754913

\section{Appendix 1}

Target and distractor words used in Experiment.

\begin{tabular}{l|c|c|c|c}
\hline \multicolumn{2}{c}{ Sarget Word (Gender) } & \multicolumn{3}{c}{ Distractor Type } \\
& Overlap & No Overlap & Overlap & No Overlap \\
\hline Besen (M) & Berg & Markt & Beere & Hupe \\
Adler (M) & Adel & Kredit & Ader & Huldigung \\
Arm (M) & Argwohn & Koffer & Armut & Butter \\
Axt (F) & Aktion & Witterung & Akzent & Wind \\
Banane (F) & Bank & Trägheit & Bann & Kittel \\
Baum (M) & Bau & Zucker & Baustelle & Kachel \\
Birne (F) & Binde & Hantel & Biber & Tüftler \\
Blume (F) & Bluse & Erwartung & Blutegel & Karpfen \\
Bombe (F) & Borste & Last & Bock & Garten \\
Brunnen (M) & Bruch & Schall & Bruchbude & Schalotte \\
Brust (F) & Brutalität & Tapete & Bruder & Staat \\
Bürste (F) & Bürde & Nahrung & Bürger & Handel \\
Bus (M) & Busch & Filter & Butter & Kammer \\
& & & &
\end{tabular}




\begin{tabular}{|c|c|c|c|c|}
\hline Erdbeere (F) & Erde & Staffelei & Erwerb & Kalk \\
\hline Erdnuß (F) & Erwartung & Strafe & Erfolg & Bann \\
\hline Feder (F) & Fee & Gießkanne & Fehler & Hanf \\
\hline Finger (M) & Filz & Busch & Firma & Bruchbude \\
\hline Fisch (M) & Filter & Adel & Finsternis & Baustelle \\
\hline Fliege (F) & Fliese & Kasse & Flieder & Strahl \\
\hline Gabel (F) & Gabe & Erde & Garten & Erwerb \\
\hline Geist (M) & Geier & Pickel & Geige & Haft \\
\hline Gitarre (F) & Gießkanne & Bank & Gipfel & Kessel \\
\hline Hamburger (M) & Hammel & Palast & Haltung & Knolle \\
\hline Hammer (M) & Hals & Bruch & Haft & Geige \\
\hline Hand (F) & Hantel & Brutalität & Hanf & Biber \\
\hline Harfe (F) & Harke & Tüte & Handel & Schaum \\
\hline Hubschrauber (M) & Hunger & Kaffee & Huldigung & Nase \\
\hline Hut (M) & Huf & Bau & Hupe & Mannschaft \\
\hline Kaktus (M) & Kaffee & Geier & Kachel & Beere \\
\hline Kamm (M) & Kampf & Wunsch & Kammer & Vorlage \\
\hline Kartoffel (F) & Karre & Fee & Karpfen & Leim \\
\hline Kassette (F) & Kasse & Bürde & Kalk & Gipfel \\
\hline Kette (F) & Kelle & Waffe & Kessel & Lachs \\
\hline Kirsche (F) & Kiste & Stange & Kittel & Napf \\
\hline Knoten (M) & Knoblauch & Lehm & Knolle & Firma \\
\hline Korb (M) & Koffer & Hals & Konditorei & Tracht \\
\hline Krebs (M) & Kredit & Nabel & Creme & Schwarte \\
\hline Lampe (F) & Last & Urkunde & Lachs & Träger \\
\hline Leiter (F) & Leitung & Gabe & Leim & Tanz \\
\hline Leopard (M) & Lehm & Schwager & Lehre & Wurst \\
\hline Mantel (M) & Markt & Knoblauch & Mannschaft & Creme \\
\hline Matrose (M) & Mangel & Filz & Matratze & Lehre \\
\hline Mixer (M) & Mist & Kampf & Milch & Haltung \\
\hline Nadel (F) & Nahrung & Kiste & Napf & Bock \\
\hline Nagel (M) & Nabel & Termin & Nase & Pinie \\
\hline
\end{tabular}




\begin{tabular}{|c|c|c|c|c|}
\hline Panzer (M) & Palast & Mist & Pappe & Milch \\
\hline Pilz (M) & Pilger & Mangel & Pinie & Armut \\
\hline Pinsel (M) & Pickel & Argwohn & Pille & Matratze \\
\hline Rakete (F) & Rache & Schau & Radar & Urlaub \\
\hline Schalter (M) & Schall & Berg & Schalotte & Zunge \\
\hline Schaufel (F) & Schau & Karre & Schaum & Radar \\
\hline Schwan (M) & Schwager & Pilger & Schwarte & Pille \\
\hline Spiegel (M) & Spieß & Vorstand & Spinne & Tendenz \\
\hline Stadt (F) & Stange & Fliese & Stall & Blutegel \\
\hline Statue (F) & Staffelei & Kelle & Staat & Flieder \\
\hline Straße (F) & Strafe & Bluse & Strahl & Erfolg \\
\hline Tasse (F) & Tapete & Aktion & Tanz & Fehler \\
\hline Teppich (M) & Termin & Hunger & Tendenz & Wahl \\
\hline Traktor (M) & Trafo & Huf & Tracht & Spinne \\
\hline Träne (F) & Trägheit & Binde & Träger & Wald \\
\hline Trompete (F) & Trophäe & Wand & Troll & Akzent \\
\hline Tür (F) & Tüte & Harke & Tüftler & Bruder \\
\hline Uhr (F) & Urkunde & Rache & Urlaub & Wandel \\
\hline Vogel (M) & Vorstand & Wahn & Vorlage & Ader \\
\hline Vulkan (M) & Wunsch & Trafo & Wurst & Pappe \\
\hline Waffel (F) & Waffe & Leitung & Wandel & Troll \\
\hline Wagen (M) & Wahn & Spieß & Wahl & Konditorei \\
\hline Walnuss (F) & Wand & Borste & Wald & Bürger \\
\hline Windel (F) & Witterung & Trophäe & Wind & Stall \\
\hline Zug (M) & Zucker & Hammel & Zunge & Finsternis \\
\hline
\end{tabular}

